\title{
Going Digital in Pandemic
}

\section{Anahita Punj* \\ Department of Periodontics, Army College of Dental Sciences, India}

*Corresponding author: Anahita Punj, Department of Periodontics, Army College of Dental Sciences Jawahar Nagar, Chennapur-CRPF Road, Secunderabad, India, Email: anahitapunj@ gmail.com

\section{Editorial}

The COVID-19 pandemic has made us crawl back to our homes and provided an opportunity to pause and reflect to what has happened through these millennial years. The wastage of natural resources, the pollution created by us and wastage of food, products and plastic is all a result of our ever growing greed. We are brought to a standstill as we had become used to running $24 \times 7$, thinking it to be normal. We forgot to cherish our friendly beings in our surroundings. The only thing important which is left untouched in this pandemic is communication, thanks to the internet and mobile phone in this digital age. The digital age started way before, but its use and applicability is being realised more so during this pandemic. Today, we are waiting to burst out of our comfortable homes and trod the roads of the unknown. Seldom was a human made to restrict and limit themselves to their territories in such a way ever. This made us cherish the chirping birds, peacocks, monkeys swinging from tree branches and the stray dogs meeting and greeting you with their wagging tails on the way.

Today, the human race is going through a change emotionally, mentally, financially, and politically. There is a change in our thinking. A new challenge is there in front of us. The pandemic created confusion and fear of unfolding of our future. Many were victims of losing their jobs. For instance, in India the unemployment rate rose from $6 \%$ to $27 \%$ amid the lockdown and reduced to $24 \%$ post partial lifting of the lockdown. Amid this scenario, many industries including the healthcare industry were hit tremendously with fear of contracting the disease, the financial implications and unavailability of adequate resources to tide over the pandemic. This gave a boosting spurt to the use of already existing digital technology in all spheres. The IT sector which already had the concept of remote work, conveniently shifted to fulltime homeworking. The fitness industry and others were also quick to follow this trend. The healthcare industry switched to digital consultations and started revamping their system in order to make everything contact less. The supermarkets were already available online through various online platforms. Currently, industries are in the process of recovery and revamping themselves for future pandemics.

The lockdown enforcements had a momentous impact on the teaching fraternity as well. While the schools and colleges are closed and examinations postponed or cancelled, the challenge remains as how to change the system to enforce a mechanism or system which would not defer the learning of the upcoming generation. The teaching in the healthcare profession made use of various existing digital platforms but, what remains challenging, is the delivery and transfer of knowledge and application of the practical skills in the actual workspace. For instance, the dental students can't be expected to learn practical exercises of giving local anesthesia or reflecting a flap just based on theoretical knowledge till they practice on an actual patient. Even though dummy models and simulators are helpful, but the physical presence of a mentor or the so called 'human touch' would be lacking. My personal experience with online teaching and consultation made me realise that probably this concept is here to stay, and going digital probably is one way to bring about a change in our practice. However, this has led to a pandemic of information, i.e. 'infodemic' thanks to the digital platforms and non-stop webinars. In the dental setting, the investment in digital scanners, CBCT, OPG machines, touch free dispensers, extensive protective barriers in dental practice are making more sense today than ever. The technology of 3-D printing has been used creatively to manufacture ventilators and creating innovative products to prevent aerosol transmission in work space. The importance of health and practicing hygiene has regained its lost importance which was probably taken for granted and forgotten by many. 
I feel this has brought a new way of working remotely in the comfort of their home with mere requirements of internet and electricity. On the flip side, it has challenged those who do not have access to these basic necessities, facilities or are digitally challenged. This also brings us to weigh the pros and cons of digitisation and to limit its use wherever essential and not become enslaved by it. Digitisation has its own sideeffects which would have to be modulated and corrected over the upcoming years. The point is that, although, we aim to see the silver lining in the present COVID pandemic by assuring ourselves that this too shall pass. The truth is, we probably have to live with it for a long time and who knows when another pandemic or a situation akin to it may arise. Going Digital is not the ultimate answer but it's a solution which should be worked upon to build a new way of teaching, working and providing care for the patients and each other. It's time that all of us upgrade ourselves and be a part of this digital revolution, as this would be an indispensable tool in the future. 